\title{
The use of the dexamethasone suppression test in the evaluation of depression: A re-examination
}

\author{
ROBERT J. BIELSKI, M.D. \\ East Lansing, Michigan \\ GREGORY A. HOLMES, PH.D. \\ Lewiston, Maine \\ CHARLES L. WEST, PH.D. \\ CHRISTINE L. SHAFER, M.D \\ East Lansing, Michigan
}

The clinical and research usefulness of the dexamethasone suppression test (DST) in diagnosis of endogenous depression has become the subject of considerable controversy. Following the original report on the standardization of this test, subsequent studies often deviated in significant ways in methodology. The present study of 107 subjects was undertaken to determine the specificity and sensitivity of the DST utilizing a methodology similar to that of the original report. The sensitivity of the DST was 57 percent for definite endogenous depressive disorder and 7 percent for nonendogenous depression. The specificity and predictive value of the DST for endogenous depression were 82 percent and 89 percent, respectively. These results are quite comparable to those of the original standardization study. These data support the validity of the DST as a biologic marker for endogenous depression, and, when properly utilized, the test can be an effective adjunctive tool for confirming the clinical diagnosis of this disorder.

The clinical and research utility of the dexamethasone suppression test (DST) in psychiatry recently has become quite controversial. Abnormal cortisol secretion, as measured by the DST, has been thought by some researchers to be a biologic marker of melancholic depression. The clinical diagnosis of melancholic depression is made when the history and examination of the patient reveal a combination of such symptoms as a depressed mood distinct from grief, lack of reactivity, diurnal mood variation, loss of interest and pleasure, feelings of guilt or self reproach, early morning waking or middle of sleep insomnia, psychomotor retardation or agitation, poor appetite, and nondieting weight loss. ${ }^{1}$ While some believe that this diagnosis can be aided by appropriate laboratory testing, with the DST having reasonable predictive capabilities in a preselected population, ${ }^{2}$ other authors ${ }^{3-5}$ have questioned the sensitivity and specificity of the test.

Most of the controversy surrounding the applicability of the DST in the clinical evaluation of depression has focused on its specificity. Several researchers have challenged Carroll and associates' ${ }^{2}$ report of a 96-percent specificity rate for melancholic depression with their own findings of abnormal cortisol secretion in patients with primary degenerative dementia, ${ }^{6}$ panic attacks, ${ }^{7}$ nonmelancholic depression, ${ }^{5}$ separation anxiety disorders of childhood, ${ }^{8}$ bulimia, ${ }^{9}$ schizophrenia,,${ }^{3,4}$ and abstinent alcoholism. ${ }^{5}$

There are two major difficulties in comparing information among DST studies. First, many of the studies that suggested that abnormal cortisol secretion is not specific to melancholic depression have used small sample sizes. Second, no uniform research methodology was used in the respective studies; the methodologic differences include different diagnostic classification systems for assigning patients to research groups as well as varying procedures for patient exclusion.

The purpose of the present study was to determine the cortisol suppression rates for endogenous and nonendogenous depression in an independent, large sample of patients using classification and exclusion procedures similar to those employed by Carroll and associates. ${ }^{2}$ 


\section{Subjects and methods}

\section{Patient selection}

The subjects for the present study consisted of 107 patients who presented with a chief complaint of depression at a consortium of outpatient and inpatient psychiatric facilities in a large, Midwestern university. The demographic characteristics of the patient sample are displayed in Table 1. Patients' ages ranged between 18 and 65 years. All but 6 of the subjects were seen on an outpatient basis, and all were free of medical illnesses and medications that were reported by Carroll and associates ${ }^{2}$ to invalidate the DST. Exclusion criteria also included a history of bipolar depression or concurrent diagnosis of alcoholism, schizophrenia, organic brain syndrome, or anorexia nervosa. Socioeconomically, this group of subjects primarily was middle classed. Diagnostically, subjects met the criteria for one or more categories for primary depression (Table 2).

\section{Rater training and assessment of clinical features} The interviewer/raters for this project were trained

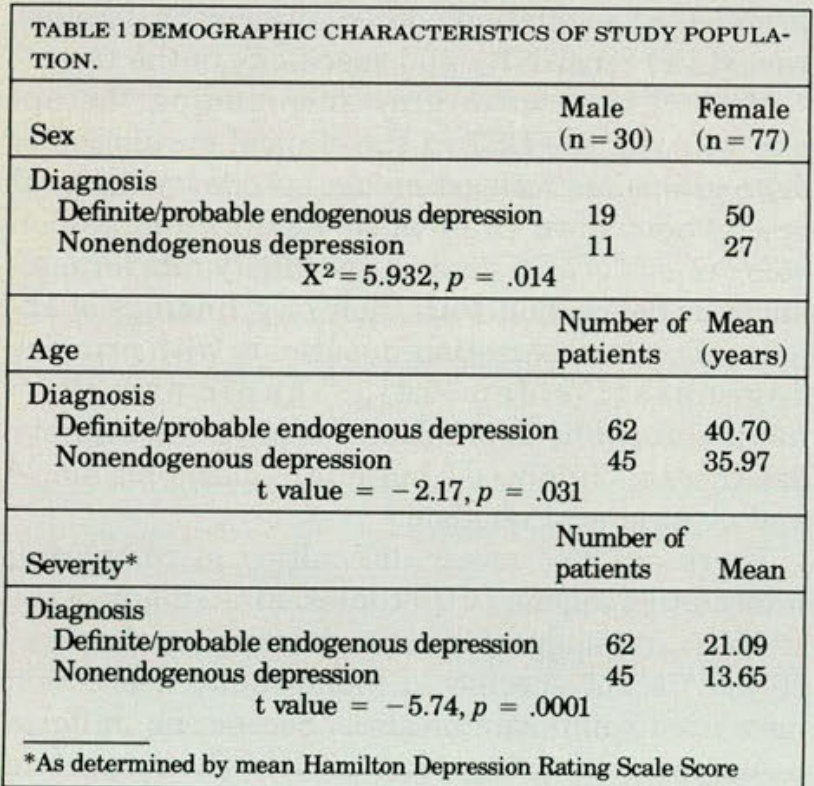

using materials and procedures drawn from a training program specifically developed for the Research Diagnostic Criteria (RDC) program. ${ }^{1} \mathrm{~A}$ complete discussion of the training procedures and results has been provided elsewhere. ${ }^{10}$ Patients were assessed for current symptomatology using Part I of the Schedule for Affective Disorders and Schizophrenia (SADS), ${ }^{11}$ a semistructured interview for psychiatric disorders. They then were diagnosed according to the RDC.

\section{Dexamethasone suppression testing}

Following the diagnostic interview, each subject was given the DST. Each subject received $1 \mathrm{mg}$. of dexamethasone orally at 11 p.m., and a single blood draw was performed at 4 p.m. the next day. Cortisol sampling at 11 p.m. was omitted to avoid inconvenience for this mostly outpatient group. Plasma cortisol levels were assayed using a GammaCoat (125I) radioimmunoassay kit (Clinical Assays). The assay was compared periodically during the study with the competitive protein-binding procedure of Carroll's group. ${ }^{2}$ While there was some variation across lot numbers of the radioimmunoassay kit, for the entire sample a cortisol level of $4.6 \mu \mathrm{g} . / \mathrm{dl}$. found with GammaCoat ( $\left.{ }^{125} \mathrm{I}\right)$ was equivalent to 5.0 $\mu \mathrm{g} . / \mathrm{dl}$. using competitive protein binding. Therefore, in the current study, a serum cortisol level $>4.6 \mu \mathrm{g} . / \mathrm{dl}$. was used as the criterion for cortisol nonsuppression.

\section{Time period for analysis}

SADS item ratings for the week prior to evaluation were used for the statistical analyses in this study. The decision to select the most immediate severity ratings of clinical features was based on the hypothesis that DST nonsuppression is a transitory variable, whose possible clinical concomitants are most likely to be identified when DST response and clinical phenomenology are measured within a close time frame.

TABLE 2. DIAGNOSTIC PERFORMANCE OF DST ACCORDING TO RDC CATEGORIES.

\begin{tabular}{|c|c|c|c|c|c|c|}
\hline Category & $\begin{array}{l}\text { Number of } \\
\text { subjects } \\
\text { (total }=107)\end{array}$ & $\begin{array}{c}\text { Prevalence } \\
\text { (percent) }\end{array}$ & $\begin{array}{l}\text { Positive } \\
\text { DST } \\
\text { (number) }\end{array}$ & $\begin{array}{c}\text { Sensitivity } \\
\text { (percent) }\end{array}$ & $\begin{array}{l}\text { Specificity } \\
\text { (percent) }\end{array}$ & $\begin{array}{c}\text { Predictive } \\
\text { value } \\
\text { (percent) }\end{array}$ \\
\hline $\begin{array}{l}\text { Major depressive disorder (MDD) } \\
\text { Definite and probable } \\
\text { Definite } \\
\text { Probable }\end{array}$ & $\begin{array}{l}82 \\
64 \\
18\end{array}$ & $\begin{array}{l}77 \\
59 \\
17\end{array}$ & $\begin{array}{r}25 \\
22 \\
3\end{array}$ & $\begin{array}{l}30 \\
29 \\
17\end{array}$ & $\begin{array}{l}92 \\
88 \\
73\end{array}$ & 92 \\
\hline $\begin{array}{l}\text { Endogenous MDD } \\
\text { Definite and probable } \\
\text { Definite } \\
\text { Probable }\end{array}$ & $\begin{array}{l}62 \\
30 \\
32\end{array}$ & $\begin{array}{l}58 \\
26 \\
31\end{array}$ & $\begin{array}{r}24 \\
17 \\
7\end{array}$ & $\begin{array}{l}39 \\
57 \\
22\end{array}$ & $\begin{array}{l}82 \\
81 \\
76\end{array}$ & 89 \\
\hline
\end{tabular}




\section{Results}

\section{Response to dexamethasone}

Twenty-seven patients failed to suppress normally on the DST, with 24 having cortisol values $>5.0$ $\mu \mathrm{g} . / \mathrm{dl}$. Of the 80 suppressors in the study, $63 \mathrm{had}$ cortisol values $\leqslant 2 \mu \mathrm{g}$./dl., 9 between 2.1 and 3.0 $\mu \mathrm{g} . / \mathrm{dl}$., and 8 between 3.1 and $4.0 \mu \mathrm{g} . / \mathrm{dl}$.

Table 2 presents the nonsuppression rates for each RDC diagnostic category. The sensitivity of the DST ( 53 percent [16/30] for definite endogenous depression, 25 percent [8/32] for probable endogenous depression, and 7 percent [3/45] for nonendogenous depression [nonendogenous major, intermittent, or minor depressive disorder]) was comparable to those reported by Carroll and associates. $^{2}$

The specificity and predictive value of the DST for probable and definite endogenous depression (82 percent and 89 percent, respectively) determined in the present study also are comparable to those reported by Carroll's group. ${ }^{2}$

Table 3 demonstrates the nonsuppression rate for various RDC subgroups. Interestingly, 24 percent (20/82) of our subjects with RDC major depressive disorders were nonendogenous. Again, this finding was quite comparable with the 31 percent reported by Carroll and associates. ${ }^{2}$

In terms of treatment response in the endogenous group, 10 of 13 DST nonsuppressors ( 77 percent) responded to desipramine, while 10 of 21 suppressors (48 percent) experienced a favorable response. This difference fell just short of statistical significance. These data are being prepared for publication in more detail.

\section{Conclusions}

These data support the validity of the DST as a biologic marker both for major depressive disorder and endogenous depressive disorder. While the specificity of the DST was similar among four categories (MDD [definite and probable], MDD [definite], endogenous MDD [definite and probable], and endogenous MDD [definite]), the sensitivity of this test was highest in the definite endogenous group. It is important to note that only 4-p.m. cortisol levels were determined. The addition of 11-p.m. samples would be expected to increase sensitivity somewhat. The high percentage of endogenous subjects included in this study reflects prescreening that occurred prior to evaluation for the protocol.

These data are strikingly similar to the results reported by Carroll and associates. ${ }^{2}$ While both of our research centers are located in Michigan, the authors of this article believe that the similarity in our data reflects the similar application of diagnostic criteria and the use of similar methodology

\begin{tabular}{|c|c|c|c|}
\hline \multirow[b]{2}{*}{ Diagnosis } & \multirow{2}{*}{$\begin{array}{l}\text { Number of } \\
\text { subjects }\end{array}$} & \multicolumn{2}{|c|}{ Positive DST } \\
\hline & & Number & Percent \\
\hline \multicolumn{4}{|l|}{$\begin{array}{l}\text { Major depressive } \\
\text { disorder (MDD) }\end{array}$} \\
\hline Definite and probable & 82 & 25 & 30 \\
\hline Definite & 64 & 22 & 34 \\
\hline Probable & 18 & 3 & 17 \\
\hline \multicolumn{4}{|l|}{ Endogenous MDD } \\
\hline Definite and probable & 62 & 24 & 39 \\
\hline Definite & 30 & 17 & 57 \\
\hline Probable & 32 & 7 & 22 \\
\hline \multicolumn{4}{|l|}{ Nonendogenous disorders } \\
\hline $\begin{array}{l}\text { Intermittent depressive } \\
\text { disorder }\end{array}$ & 12 & 0 & 0 \\
\hline Minor depressive & & & \\
\hline disorder & 13 & 2 & 15 \\
\hline
\end{tabular}

(that is, exclusion criteria and cortisol assay procedure). We believe that much of the controversy regarding the validity of the DST has been generated from studies utilizing methodologies that differed from those of Carroll's group. It is also interesting to note that our sample size is large as compared to those of many DST studies.

In addition to the crossectional studies to date, further studies that include family history, course over time (including serial diagnoses), history of treatment response, and correlation with other biologic markers clearly are necessary. ${ }^{12}$ Nonetheless, we believe that the DST can be a useful, adjunctive tool for confirming the clinical diagnosis of endogenous depression. These data, combined with those from studies ${ }^{13-16}$ demonstrating a more favorable response to somatic treatments among DST nonsuppressors, suggest that depressed patients most likely to respond to antidepressant medication are those with both a clinical diagnosis of endogenous depression and an abnormal response to the DST. Additional studies of the efficacy of the DST in monitoring response to treatment, in predicting relapse, and in predicting suicide hopefully will resolve the controversy regarding the role of this laboratory test in psychiatry. ${ }^{12,17}$

\footnotetext{
1. Endicott, J, and Spitzer, R.L.: Use of research diagnostic criteria and the Schedule for Affective Disorders and Schizophrenia to study affective disorders. Am J Psychiatry 136:52-6, Jan 79

2. Carroll, B.J., et al: A specific laboratory test for the diagnosis of melancholia. Standardization, validation, and clinical utility. Arch Gen Psychiatry 38:15-22, Jan 81

3. Dewan, M.J., et al.: Abnormal dexamethasone suppression test results in chronic schizophrenic patients. Am J Psychiatry 139:1501-3, Nov 82 4. Castro, P., et al: Abnormal DST results in patients with chronic
} 
schizophrenia (letter). Am J Psychiatry 140:1261, Sep 83

5. Coppen, A., et al.: Dexamethasone suppression test in depression and other psychiatric illness. Br J Psychiatry 142:498-504, May 83

6. Raskind, M., et al.: Dexamethasone suppression test and cortisol circadian rhythm in primary degenerative dementia. Am J Psychiatry 11:1468-71, Nov 82

7. Sheehan, D.V., et al.: Panic attacks and the dexamethasone suppression test. Am J Psychiatry 140:1063-4, Aug 83

8. Livingston, R., Reis, C.J., and Ringdahl, I.C.: Abnormal dexamethasone suppression test in depressed and nondepressed children. Am J Psychiatry 141:106-8, Jan 84

9. Hudson, J.I., et al.: Hypothalamic-pituitary-adrenal axis hyperactivity in bulimia. Psychiatry Res 8:111-7, Feb 83

10. Holmes, G.A., et al.: Teaching students to diagnose depression. A pilot study of research diagnostic criteria. Prof Psychol Res Prac 14:717-9, Dec 83

11. Endicott, J., and Spitzer, R.L.: A diagnostic interview. The Schedule for Affective Disorders and Schizophrenia. Arch Gen Psychiatry $35: 837-44$, Jul 78

12. Carroll, B.J.: Dexamethasone suppression test. A review of contemporary confusion. J Clin Psychiatry 46:13-24, Feb 85

13. Brown, W.A., and Shuey, I.: Response to dexamethasone and subtype of depression. Arch Gen Psychiatry 37:747-51, Jul 80

14. Ames, D., et al:: A study of the dexamethasone suppression test in hospitalized depressed patients. Br J Psychiatry 144:311-3, Mar 84

15. Nelson, W.H., et al.: Hypothalamic-pituitary-adrenal axis activity and tricyclic response in major depression. Arch Gen Psychiatry 39:1033-6, Sep 82

16. Ettigi, P.G., et al.: d-amphetamine response and dexamethasone suppression test as predictors of treatment outcome in unipolar depression. Biol Psychiatry 18:499-504, Apr 83

17. Hirschfeld, R.M.A., Koslow, S.H., and Kupfer, D.J.: The clinical utility of the dexamethasone suppression test in psychiatry. Summary of a National Institute of Mental Health Workshop. JAMA 250:2172-4, 28 Oct 83

Accepted for publication in July 1986. Updating, as necessary, has been done by the authors.

Dr. Bielski is an associate professor in the Department of Psychiatry at Michigan State University, East Lansing, Michigan. Dr. Holmes is a behavioral scientist, family practice residency program, Central Maine Medical Center, Lewiston, Maine. Dr. West was a graduate student at MSU at the time this paper was written. Dr. Shafer is an assistant professor in the Department of Psychiatry at MSU.

Dr. Bielski, Michigan State University, Department of Psychiatry, East Fee Hall, East Lansing, Michigan 48824-1316. 